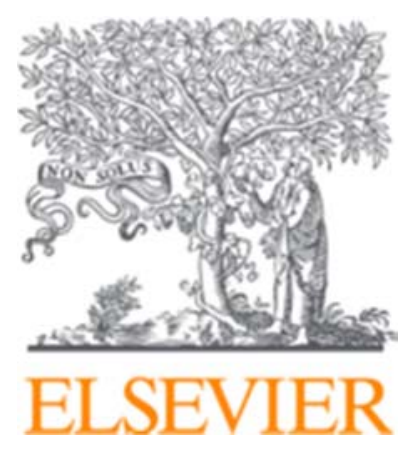

The Journal of Academic Librarianship

Volume 45, Issue 4, July 2019, Pages 394-405

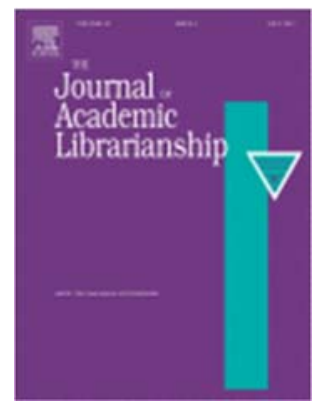

\title{
Determinants of perceived usefulness of social media in university libraries: Subjective norm, image and voluntariness as indicators
}

Author links open overlay panel Rolandlzuagbe

Goodlucklfijeh $^{\mathrm{a}}$

Edith I.Izuagbe-Roland

Olajumoke RebeccaOlawoyin ${ }^{a}$

Lilofa OsamenfaOgiamien $^{\circ}$

Covenant University, Nigeria

Home Science Association School, Nigeria

Benson Idahosa University, Nigeria 
Received 7 September 2018, Revised 31 January 2019, Accepted 18 March 2019, Available online 21 May 2019.

Show less

https://doi.org/10.1016/j.acalib.2019.03.006Get rights and content

\section{Abstract}

The study examined the role of social influence process of subjective norm, image and voluntariness on perceived usefulness of social media (PUSM) in private university libraries. The quest to ascertain the impact of the social factor in a profit-motivated environment prompted the study. The descriptive research design alongside multistage sampling procedures was applied and the questionnaire method was used for data collection. One hundred and ninety (190) librarians, selected from 13 private university libraries provided the data, out of which 184 copies of the instrument were correctly filled and returned, representing 96.8 per cent return rate. Statistical tools like simple percentage, mean and standard deviation of the Special Package for the Social Sciences (SPSS) were employed to analyse the research questions. Results shown that image was the strongest determinant among the proposed social factors of PUSM, followed by subjective norm. While voluntariness was a weak predictor of PUSM, the overall PUSM of librarians in the private university domain in the studied region was very high. This implies that the social factor is significant predictor of technology adoption in the private university library environment. Accordingly, the study concluded that if the performance potentials of social media are consciously communicated and imbibed by librarians through adequate training, whether or not private universities operate in a mandatory environment, PUSM of librarians will remain positively high.

- Previous article in issue

- Next article in issue

\section{Keywords}


Social influence process

Perceived usefulness of social media (PUSM)

Subjective norm

Image

Voluntariness

Private university libraries

(C) 2019 Published by Elsevier Inc.

- About ScienceDirect

- Remote access

- Shopping cart

- Advertise

- Contact and support

- Terms and conditions

- Privacy policy 